\title{
Using data analytics to further understand the role that boredom, loneliness, social anxiety, social gratification, and social relationships (BRAG) play in a driver's decision to text
}

\author{
Nathan White, Central Washington University, USA, whiten1@cwu.edu \\ Yair Levy, Nova Southeastern University, USA, levyy@nova.edu \\ Steven R. Terrell, Nova Southeastern University, USA, terrell@nova.edu \\ Steve Bronsburg, Nova Southeastern University, USA, bronsbur@nova.edu
}

\begin{abstract}
Texting while driving is a growing problem that current efforts have failed to curtail. This behavior has serious, and sometimes fatal, consequences, and the factors that cause a driver to text are not well understood. This study investigates the influence that boredom, social relationships, social anxiety, and social gratification (BRAG) have upon the texting driver. A survey instrument was used to collect data from 297 respondents at a mid-sized regional university in the Pacific North west of the United States. The data was evaluated with PLS-SEM, which indicated that social gratification plays a very significant role in a driver's decision to text. Additionally, data visualization techniques were used to gain additional knowledge from the data. The analysis with these techniques indicated that social anxiety may also play a role in a driver's decision to text.
\end{abstract}

Keywords: Texting while driving; data visualization; social gratification; social relationships; boredom; social anxiety.

\section{Introduction}

Sending and receiving text messages is one of the most common uses of cell phones, which over $80 \%$ of adult cell phone owners engaging in this activity (Duggan \& Rainie, 2012; Snowden, 2006). Additionally, 50\% of all teens text on a daily basis (Lenhart, 2012). Unfortunately, nearly half of all drivers, adult and teen, have admitted to texting while driving (TWD) (Cooper, Yager, \& Chrysler, 2011; Strayer, Watson, \& Drews, 2011). Because of the serious negative impact that texting has upon driver performance, the texting driver is involved in fatal crashes up to 23 times more than the non-texting driver (Olson, Hanowski, Hickman, \& Bocanegra, 2009; RudinBrown, Young, Patten, Lenné, \& Ceci, 2012; Wilson \& Stimpson, 2010). In 2013, 14\% of all fatal crashes were attributed to cell-phone related distractions (Distracted Driving 2013, 2015).

Unfortunately, the efforts to solve this problem have proven to be woefully inadequate. Within the United States, TWD is still a serious concern, even though 46 states and the District of Columbia have passed laws that ban TWD ("Distracted driving," 2016). These laws have not resulted in a reduction in fatalities associated with TWD, and may possibly be increasing the 
number of crashed caused by a driver that texts (Braitman \& McCartt, 2010; Gostin \& Jacobson, 2010; Highway Loss Data Institute, 2010; Smith, Benden, \& Lee, 2012)

\section{Problem statement}

The research problem that this study addressed is the increase in automobile accidents attributed to TWD (USDOT, 2010; Wilson \& Stimpson, 2010). Given the relative newness of this problem, it is not surprising that there is no consensus on the motivations that lead drivers to text (Nemme \& White, 2010). Viewing texting as an addiction may help provide some insight into this problem. Individuals create, develop, and maintain social relationships through their online and texting activities (McKenna, Green, \& Gleason, 2002; D. J. Reid \& Reid, 2005; Walsh, White, Hyde, \& Watson, 2008). Texting drivers may be attempting to maintain their social relationships to experience some level of social gratification or to avoid an increase in their social anxiety level (Liu, Cheung, \& Lee, 2010; Stafford, Stafford, \& Schkade, 2004). The social interaction that takes place through texting has been shown to increase drivers' social gratification (Liu et al., 2010; Stafford et al., 2004). According to Krishnatray, Singh, Raghavan, and Varma (2010), social gratification is the "gratification Internet users derive from chatting and interaction with friends and others" (p. 20).

Besides increasing social gratification, texting may also help maintain social relationships, which may in turn reduce one's level of social anxiety (Lu et al., 2011). Social anxiety can be described as "a marked concern about the impression one makes on others" (Mansell, Clark, Ehlers, \& Chen, 1999, p. 674). Socially anxious individuals have shown a preference toward using relatively low-risk communications, such as texting, to reduce their social anxiety (Caplan, 2007; $\mathrm{Lu}$ et al., 2011). In addition, prior research has indicated that an individual addicted to texting is likely to develop increasing levels of social anxiety when prevented from texting (Kim, LaRose, \& Peng, 2009; Skierkowski \& Wood, 2012). Additionally, the boredom experienced by the driver can be seen as "a state of relatively low arousal and dissatisfaction, which is attributed to an inadequately stimulating situation" (Mikulas \& Vodanovich, 1993, p. 3). The driver may be hoping to alleviate this state of discomfort through texting (Kircher, Patten, \& Ahlstrom, 2011; Leung, 2008).

Regardless of whether drivers are attempting to reduce their social anxiety, increase their social gratification, or relieve their boredom, the distraction caused by texting has had serious consequences (USDOT, 2010). The percentage of fatal crashes caused by be a distracted driver is an increasing problem (USDOT, 2010). In addition, texting drivers continue to text, despite awareness of the legal liabilities and the potentially fatal consequences of their actions (Drews, Yazdani, Godfrey, Cooper, \& Strayer, 2009; Kircher et al., 2011; O’Brien, Goodwin, \& Foss, 2010).

Whether seeking pleasure through maintaining social relationships or hoping to avoid discomfort, individuals who compulsively text have been shown to exhibit patterns of an addiction (Rutland, Sheets, \& Young, 2007). As uncovered by prior research, non-substance addiction, such as compulsive texting and compulsive use of the Internet, have been shown to have many similarities to substance abuse (Meerkerk, Van Den Eijnden, Vermulst, \& Garretsen, 2009; Rutland et al., 2007; Shaw \& Black, 2008; Young, 1998). Similar to symptoms of Internet addiction, Rutland et al. (2007) found that compulsive texters experienced withdrawal-like 
symptoms when they were not texting, used texting to relieve uncomfortable feelings, and were unsuccessful in repeated efforts to cut back or stop their messaging behavior. However, little attention has been given to texting addiction fueling the compulsive behavior of drivers who continue to text, despite evidence that the majority of drivers understand the serious, and possibly fatal, consequences of TWD (Ginsburg et al., 2008; Strayer et al., 2011).

The main goal of this research study was to validate empirically the influence of boredom, social anxiety, social relationships, and social gratification on an individual's decision to text while driving, as illustrated by the (BRAG) model depicted in Figure 1. Additionally, this study explored the moderating influence that a passenger may have upon a driver's texting behavior. Moreover, this study investigated whether drivers' perceived severity of the potentially fatal consequences of TWD influences their texting behavior. In addition, this study examined the role of key demographic variables in helping to explain a driver's texting behavior.

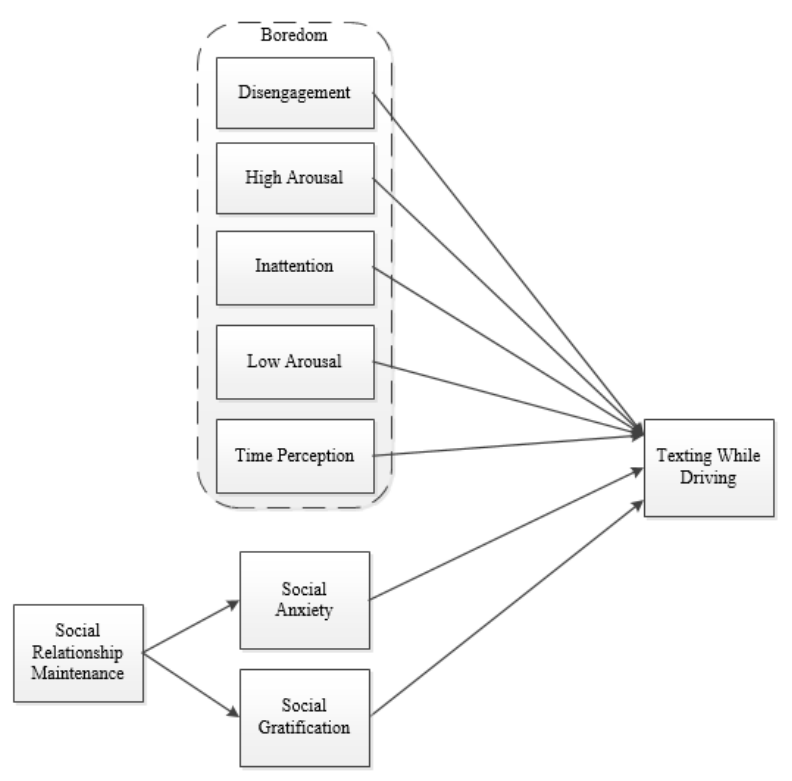

Figure 1. Conceptual research model for investigating the BRAG model.

This research study addressed the following hypotheses:

H1a-e: The discomfort from boredom will significantly increase a driver's self-reported texting.

H2: Drivers who maintain social relationships while driving will significantly decrease their social anxiety.

H3: Drivers who maintain social relationships while driving will significantly increase their social gratification.

H4: The discomfort from social anxiety will significantly increase a driver's self-reported texting.

H5: The pleasure from social gratification will significantly increase a driver's self-reported texting. 


\section{Methodology}

This study was a descriptive-quantitative study to describe the effect that boredom, social relationship maintenance, social anxiety, and social gratification have upon an individual's decision to text while driving. A survey methodology was used and was administered to students of a medium-sized university in the Pacific Northwest of the United States.

From a review of valid literature, previously validated survey instruments were chosen and then adapted to this study. Boredom was measured with the Multidimensional State Boredom Scale (MSBS; Fahlman, Mercer-Lynn, Flora, \& Eastwood, 2013).To measure social relationship maintenance, the five relationship items from the Self-perception of Text-message Dependency Questionnaire (Igarashi, Motoyoshi, Takai, \& Yoshida, 2008). The seven items that measure social utility of instant messaging from Hwang and Lombard (2006) were used to measure social gratification associated with texting. Social anxiety was measured with the Brief Version of the Fear of Negative Evaluation Scale (BV-FNE; Leary, 1983). Questions that measured TWD were selected from the National Highway Traffic Safety Administration's survey on distracted driving behavior. When necessary, response choices were recoded into a seven-point Likert scale to increase the accuracy of the responses (Krosnick \& Presser, 2009).

\section{Participants}

The survey instrument used for this study was distributed to the students of a medium-sized, regional university in the Pacific Northwest of the United States. Four hundred fifty-three individuals started the survey. However, 144 individuals abandoned the survey without submitting their responses. Another 12 individuals did not provide their consent. The remaining 297 respondents completed the survey in its entirety.

\section{Results}

\section{Pre-analysis Data Screening}

Prior to analyzing the results of the BRAG model, the collected data was screened for irregularities. The screening followed the guidance of Hair et al. (2014). The first step in the process was to check for missing data, of which there was none (Hair et al., 2014). The data was then screened for suspicious response patterns, such as response sets (Levy, 2008). No suspicious response patterns were detected. The final pre-analysis check used the Mahalanobis Distance statistical test to detect outliers, of which none were found.

\section{Indicator Assessment}

Once the pre-analysis data screening was completed, SmartPLS 2.0 and SPSS were used to analyze the BRAG model's indicators and data using the steps recommended by Hair et al. (2014). The first step was to determine if the reflective constructs' indicators were positively correlated. Composite reliability $\left(\rho_{\mathrm{c}}\right)$ and Cronbach's Alpha were used for this test (Hair et al., 2014; Sekaran, 2003). All constructs showed strong internal consistency. Cronbach's Alpha values ranged from a low of 0.817 to a high of 0.971 and $\rho_{\mathrm{c}}$ had similar numbers, ranging from a low of 0.8863 to a high of 0.9746 . Hair et al. (2014) then recommended that the indicatory reliability and AVE be assessed to determine convergent validity. Three indicators that were used in this study fell below the indicator reliability thresholds set by Hair et al. (2014) and were 
removed from the study. All constructs used in this study had an AVE of more than 0.50, indicating that these constructs had good convergent validity (Hair et al., 2014). Assessing the discriminant validity of the reflective constructs was the last step in assessing these indicators (Hair et al., 2014). The indicator cross loadings showed good discriminant validity as all indicators loaded to the appropriate construct.

\section{Structural Model Assessment}

To assess a structural model, Hair et al. (2014) recommended assessing the collinearity, path coefficients, coefficient of determination $\left(R^{2}\right), f^{2}$ effect size, blindfolding and predictive relevance $\left(Q^{2}\right)$, as well as the $\mathrm{q}^{2}$ effect size. The tolerance and variance inflation factor (VIF) of the BRAG model's predictor constructs is shown in Table 1. No collinearity among the constructs was detected as all tolerances were greater than 0.20 and the VIFs were below 5.0, the thresholds recommended by Hair et al. (2014). The path coefficients for the BRAG model are shown in Figure 2. Three paths from the Boredom subcomponents were not significant, while the remaining paths showed significance to at least $\mathrm{p}<0.01 . R^{2}$ values for the BRAG model's endogenous variables are shown in Table 2. Thresholds more consistent with an exploratory psychological study were used to assess the BRAG model's $R^{2}$ values, and all endogenous variables showed some predictive accuracy. Table 3 shows the $f^{2}$ effect size for the BRAG model, which shows that none of the boredom variables had a significant effect size, social anxiety had a small effect, and social gratification had a large effect. As can be seen in Table 4, the $Q^{2}$ values for the three endogenous variables showed predictive relevance. However as can be seen in Table 5, the $\mathrm{q}^{2}$ effect size for the exogenous variables showed that only social gratification had a significant predictive relevance.

Table 1. Collinearity Assessment

\begin{tabular}{lcc}
\hline \multicolumn{1}{c}{ Construct } & Tolerance & VIF \\
\hline BOR_D & .227 & 4.409 \\
BOR_HA & .639 & 1.566 \\
BOR_I & .532 & 1.879 \\
BOR_LA & .342 & 2.925 \\
BOR_TP & .377 & 2.650 \\
SA & .848 & 1.179 \\
SG & .799 & 1.252 \\
\hline
\end{tabular}




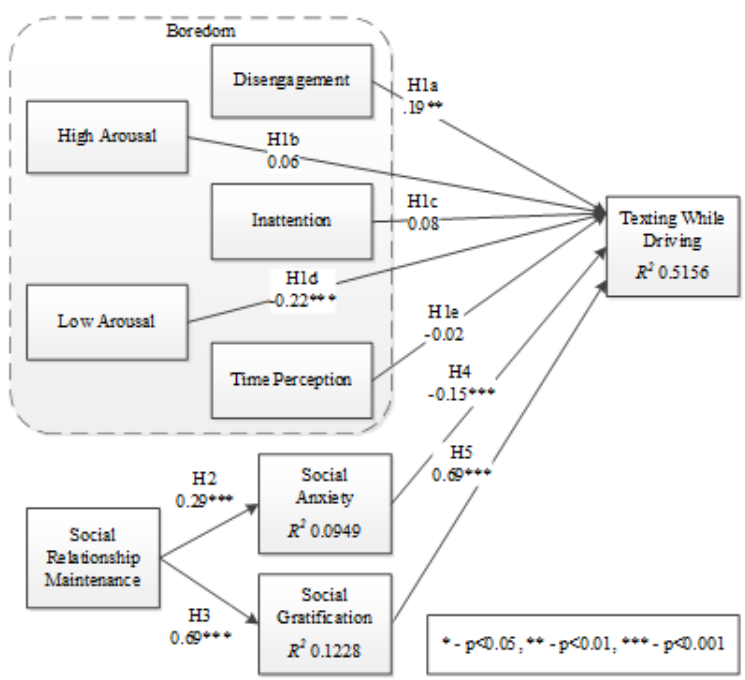

Figure 2. BRAG Model Path Coefficients

Table 2. $R^{2}$ Values

\begin{tabular}{lcc}
\hline Endogenous Variable & $\boldsymbol{R}^{2}$ & Predictive Accuracy \\
\hline SA & 0.0862 & Small \\
SG & 0.1165 & Medium \\
TWD & 0.5166 & Large \\
\hline
\end{tabular}

Table 3. $f^{2}$ Effect Size

\begin{tabular}{lcrc}
\hline & $\boldsymbol{R}^{2}$ of TWD & \multicolumn{1}{c}{$\boldsymbol{f}^{\mathbf{2}}$} & Effect Size \\
\hline BRAG & 0.5156 & & \\
Without BOR_D & 0.5191 & -0.0071 & Not Significant \\
Without BOR_HA & 0.5214 & -0.0119 & Not Significant \\
Without BOR_I & 0.5125 & 0.0065 & Not Significant \\
Without BOR_LA & 0.5082 & 0.0153 & Not Significant \\
Without BOR_TP & 0.5228 & -0.0148 & Not Significant \\
Without SA & 0.5019 & 0.0284 & Small \\
Without SG & 0.1667 & 0.7204 & Large \\
\hline
\end{tabular}

Table 4. $Q^{2}$ Values

\begin{tabular}{lc}
\hline \multicolumn{1}{c}{ Endogenous Variable } & $\boldsymbol{Q}^{2}$ \\
\hline SA & 0.0639 \\
SG & 0.0865 \\
TWD & 0.4743 \\
\hline
\end{tabular}


Table 5. $q^{2}$ Effect Size

\begin{tabular}{lcrc}
\hline & $\boldsymbol{Q}^{2}$ of TWD & \multicolumn{1}{c}{$\boldsymbol{q}^{2}$} & Effect Size \\
\hline BRAG with all main constructs & 0.4743 & & \\
Without BOR_D & 0.4749 & -0.0012 & Not Significant \\
Without BOR_HA & 0.4814 & -0.0136 & Not Significant \\
Without BOR_I & 0.4807 & -0.0123 & Not Significant \\
Without BOR_LA & 0.4689 & 0.0101 & Not Significant \\
Without BOR_TP & 0.4839 & -0.0184 & Not Significant \\
Without SA & 0.4659 & 0.0159 & Not Significant \\
Without SG & 0.1145 & 0.6843 & Large \\
\hline
\end{tabular}

\section{Demographic Analysis}

This research gathered four types of demographic information: gender, number of years the respondent had been driving, the numbers of annual miles that the respondent drove, and the number text messages the respondent sent per day. This information is summarized in Table 6. It should be noted that the data collected in not representative of the university's student body. During the 2014-2015 school year when this data was collected, females accounted for $51.1 \%$ of the student body and males accounted for $48.9 \%$ of the student body. In the survey used for this research, more females responded, 73.7\%, than males, 26.3\%. However, both males and females provided similar responses to the questions, as can be seen in Figure 3.

Table 6. Descriptive Statistics and Demographics ( $=297)$

\begin{tabular}{|c|c|c|}
\hline Item & Frequency & Percentage $(\%)$ \\
\hline \multicolumn{3}{|l|}{ Gender } \\
\hline Male & 78 & 26.3 \\
\hline Female & 219 & 73.7 \\
\hline \multicolumn{3}{|l|}{ Years Driving } \\
\hline 5 or less & 141 & 47.5 \\
\hline 6 to 10 & 89 & 30.0 \\
\hline 11 to 15 & 19 & 6.4 \\
\hline 16 to 20 & 14 & 4.7 \\
\hline More than 20 & 34 & 11.4 \\
\hline \multicolumn{3}{|l|}{ Text Message Sent per Day } \\
\hline 25 or less & 168 & 56.6 \\
\hline 26 to 50 & 58 & 19.5 \\
\hline 51 to 75 & 10 & 3.4 \\
\hline 76 to 100 & 36 & 12.1 \\
\hline More than 100 & 25 & 8.4 \\
\hline \multicolumn{3}{|l|}{ Annual Miles Driven } \\
\hline 5,000 or less & 106 & 35.7 \\
\hline 5,001 to 10,000 & 70 & 23.6 \\
\hline 10,001 to 15,000 & 75 & 25.3 \\
\hline More than 15,000 & 46 & 15.5 \\
\hline
\end{tabular}




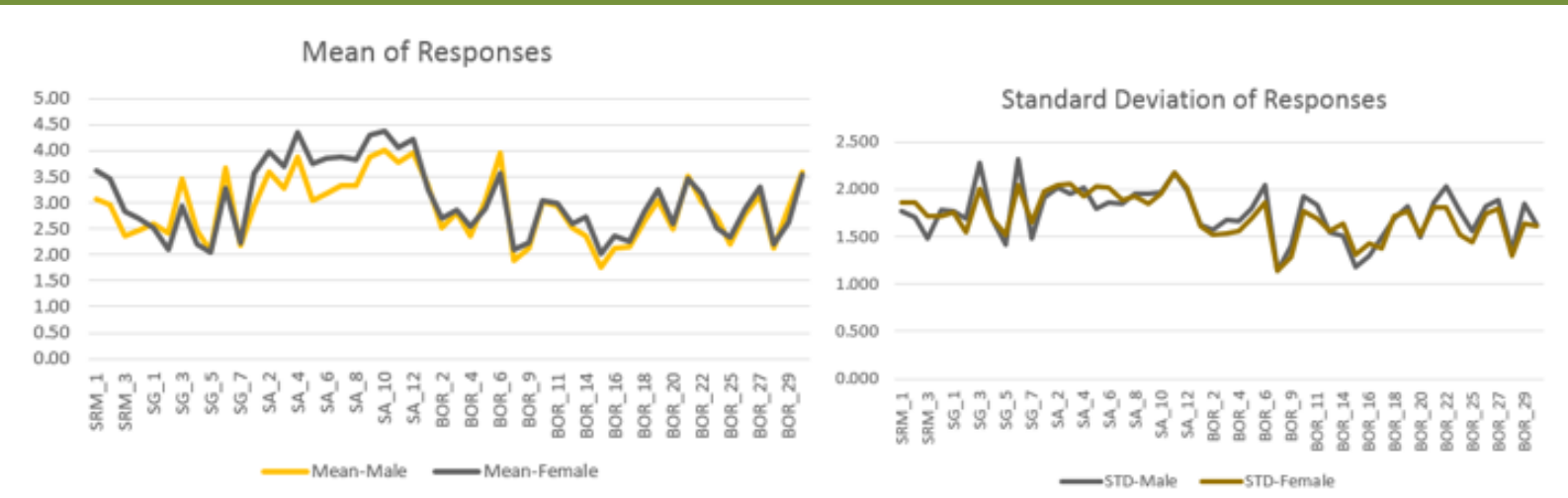

Figure 3. Comparison of Mean and Standard Deviation of Gender Responses

\section{Data Visualization Analysis}

Heat maps and radar charts were used to visualize the data in this study, which is a productive way to analyze and communicate complex quantitative ideas (Tufte, 2001). The heat maps shown in Figures $4 \mathrm{a}$ to $4 \mathrm{c}$ depict the endogenous variable TWD and the indicators of the latent variables that are directly connected to TWD. The radar charts in Figures $4 \mathrm{~d}$ to $4 \mathrm{f}$ depict TWD and these same latent variables. An analysis of these two visualizations techniques seems to confirm the findings of the structural model. Neither social anxiety nor boredom appears to significantly influence TWD, while social gratification clearly influences TWD. The heat maps and radar charts in Figure 5 were used to further analyze the role that social relationship maintenance has on social anxiety and social gratification. The heat map depicting the relationship between social anxiety and social relationship management does not show any clear relationship between the two and appears to confirm the findings from the structural model analysis. However, the radar chart for these two variables suggests that there may be a relationship. The heat map that shows the shows the indicators for social gratification and social relationship management doesn't appear to show much of a relationship between the two constructs, however the radar chart clearly shows that the two variables are significantly related. 


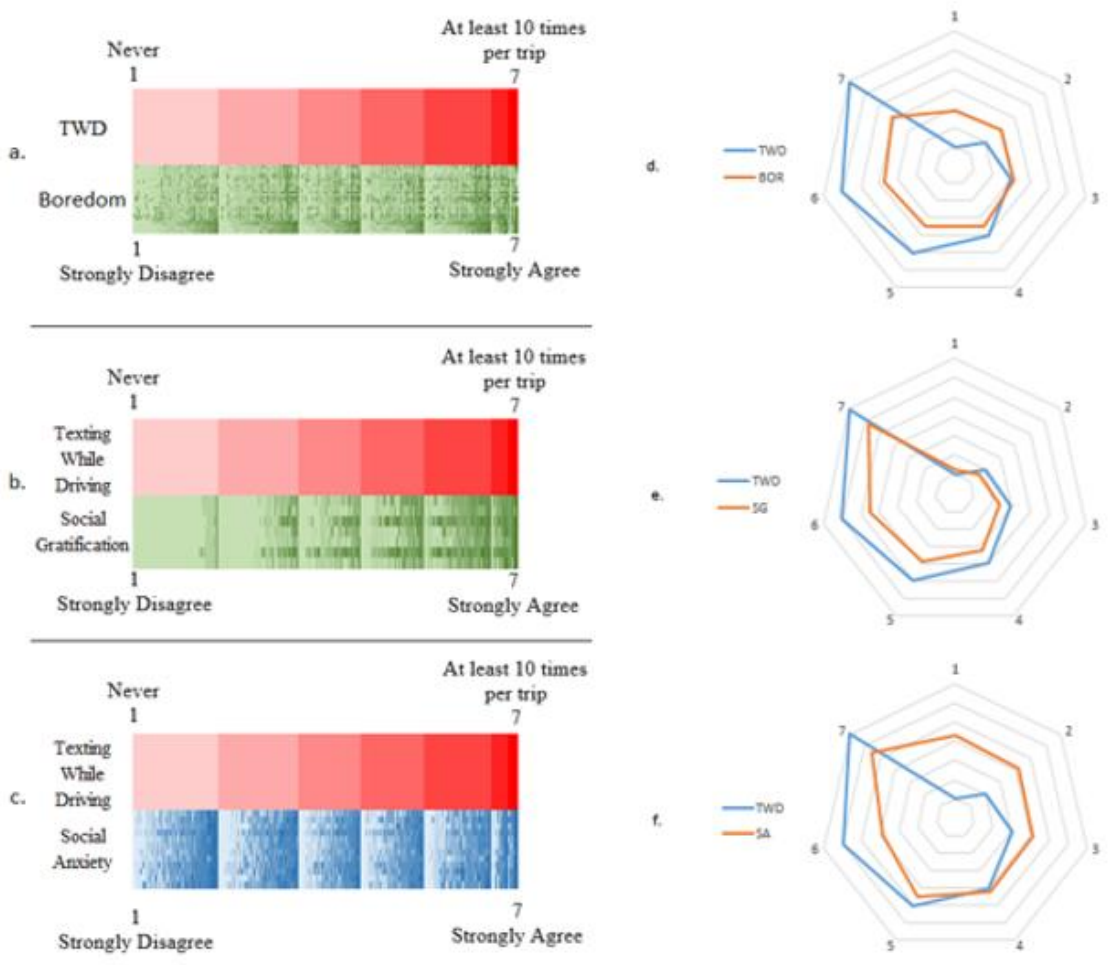

Figure 4. Visualization of TWD

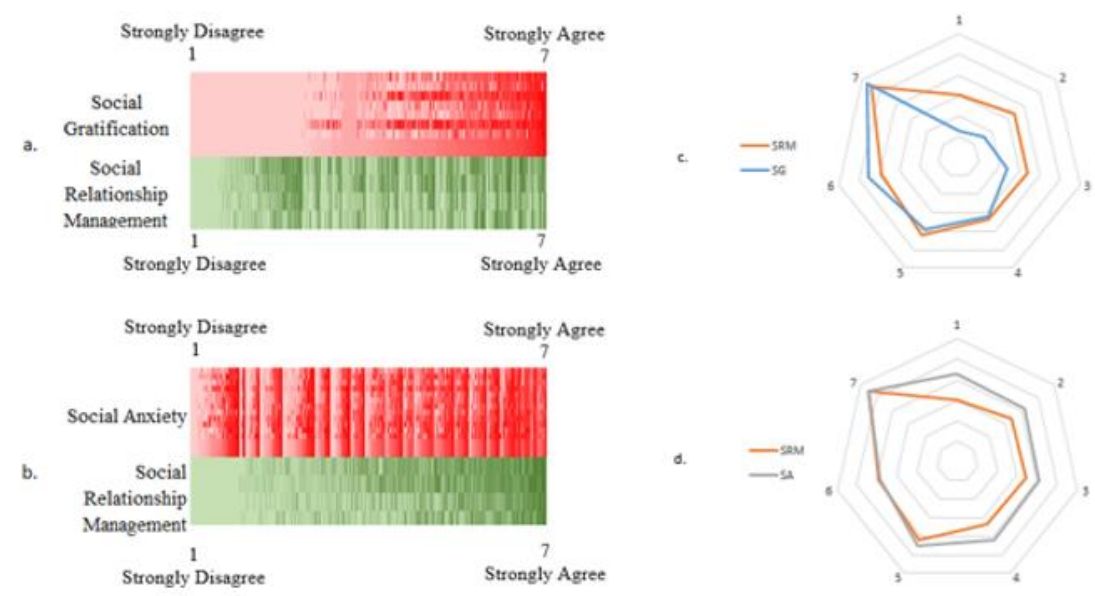

Figure 5. Visualization of SRM 


\section{Discussion}

\section{Summary of Results}

Based on the analysis of the data collected in this study, social gratification appears to play a significant role in a driver's decision to text. The tests of the hypotheses used in this study are summarized in Table 7. The testing of the first hypothesis indicates that boredom does not play a significant role in a driver's decision to text. Three subcomponents of boredom, disengagement, high arousal, and time perception, showed no significance. The two other boredom subcomponents, inattention and low arousal, had path coefficients that were significant, but neither the predictive accuracy nor the predictive relevance of these subcomponents were significant. The second and fourth hypotheses were not supported, but showed interesting results. While it was hypothesized that maintaining social relationships by TWD would reduce social anxiety, it seems that the opposite is true. Similarly, a heightened level of social anxiety did not increase a driver's texting, but it seemed to lower it. The third and fifth hypotheses were supported, indicating that social relationships and the gratification obtained by maintaining those relationships play a significant role in a driver's decision to text.

Data visualization techniques were then used to gain further insight into the data. These techniques confirmed the strong influence that social gratification has upon a driver's decision to text. These techniques also suggest that social anxiety may indeed play a role in TWD.

Table 7. Summary of Hypotheses Results

\begin{tabular}{|c|c|c|c|}
\hline & Hypotheses & Path & \multirow{7}{*}{$\begin{array}{c}\text { Results } \\
\text { Not Supported } \\
\text { Not Supported } \\
\text { Partially } \\
\text { Supported } \\
\text { Partially } \\
\text { Supported } \\
\text { Not Supported }\end{array}$} \\
\hline H1a: & \multirow{6}{*}{$\begin{array}{l}\text { The discomfort from boredom will significantly } \\
\text { increase a driver's self-reported texting. }\end{array}$} & BOR_D -> TWD & \\
\hline H1b: & & BOR_HA $\rightarrow$ TWD & \\
\hline H1c: & & BOR_I -> TWD & \\
\hline & & & \\
\hline H1d: & & BOR_LA -> TWD & \\
\hline H1e: & & BOR_TP $->$ TWD & \\
\hline $\mathrm{H} 2$ : & $\begin{array}{l}\text { Drivers who maintain social relationships while } \\
\text { driving will significantly decrease their social } \\
\text { anxiety. }\end{array}$ & SRM $->$ SA & Not Supported \\
\hline H3: & $\begin{array}{l}\text { Drivers who maintain social relationships while } \\
\text { driving will significantly increase their social } \\
\text { gratification. }\end{array}$ & SRM -> SG & Supported \\
\hline H4: & $\begin{array}{l}\text { The discomfort from social anxiety will significantly } \\
\text { increase a driver's self-reported texting. }\end{array}$ & SA $->$ TWD & Not Supported \\
\hline H5: & $\begin{array}{l}\text { The pleasure from social gratification will } \\
\text { significantly increase a driver's self-reported texting. }\end{array}$ & SG -> TWD & Supported \\
\hline
\end{tabular}

\section{Implications}

This study makes an important contribution to the information system's body of knowledge by extending prior research (F. J. M. Reid \& Reid, 2010; Rutland et al., 2007) to the texting driver. F. J. M. Reid and Reid (2010) reported that non-driving individuals use texting to maintain social relationships and reduce anxiety. Rutland et al. (2007) also reported that non-drivers used texting to relieve their anxiety. This study did not extend those findings to drivers, as data gathered in this study found that a driver's anxiety would increase if the driver was to use texting to maintain social relationships. 
Another significant contribution of this study was the development of the BRAG model that treated TWD as an addiction. An addicted individual repeats behavior that produces pleasure or helps one escape unpleasantness (Goodman, 1990). This study found that the pleasure received from social gratification is a very significant predictor of TWD.

\section{Limitations and Future Research}

The limitations of this study should be taken into account when interpreting the study's results. First, the self-reported data used in this study may not be as accurate as some form of direct observation. The generalizability of the study is also affect by the study's population and the disproportionate number of females included in the study. A broader and more diverse population should be considered for future research.

The results of this study indicate that further research is necessary to help explain why an individual continues to text and drive. While this study showed that social gratification is a strong predictor of TWD, no other pleasures were investigated. Additionally, boredom and social anxiety were the only two discomforts that were investigated, with neither showing significant correlation to TWD. Other discomforts should be investigated to see if escaping those discomforts will cause a driver to text. Furthermore, the knowledge of consequences associated TWD should be investigated to determine if this knowledge will reduce the frequency of TWD. Also, the potential impact of a passenger upon TWD should also be studied.

\section{Conclusion}

This study's main goal was to validate empirically the influence of boredom, social anxiety, social relationships, and social gratification on an individual's decision to text while driving. To accomplish this goal, the BRAG model was developed and tested. Building upon the previous work of McKenna et al. (2002), D. J. Reid and Reid (2005), as well as Leung (2008), this study investigated how texting while driving is affected by one's boredom, social anxiety, social relationships, and social gratification. This study also extended the work of Skierkowski and Wood (2012) by investigating if those factors would influence a driver's decision to text. An analysis of the data collected from 297 respondents using PLS-SEM indicated that social gratification played a significant role in a driver's decision to text. Additionally, data analytics also implied that social gratification played a significant role in a driver's decision to text.

\section{References}

Braitman, K. A., \& McCartt, A. T. (2010). National reported patterns of driver cell phone use in the United States. Traffic Injury Prevention, 11(6), 543-548.

Caplan, S. E. (2007). Relations among loneliness, social anxiety, and problematic Internet use. CyberPsychology \& Behavior, 10(2), 234-242.

Cooper, J., Yager, C., \& Chrysler, S. T. (2011). An investigation of the effects of reading and writing text-based messages while driving (Vol. 7). College Station, TX: Southwest Region University Transportation Center.

Distracted driving. (2016). Highway loss data institute. Retrieved June 3, 2016, from http://www.iihs.org/iihs/topics/laws/cellphonelaws/maphandheldcellbans 
Distracted Driving 2013. (2015). Washington, D.C.

Drews, F. A., Yazdani, H., Godfrey, C. N., Cooper, J. M., \& Strayer, D. L. (2009). Text messaging during simulated driving. Human Factors: The Journal of the Human Factors and Ergonomics Society, 51(5), 762-770.

Duggan, M., \& Rainie, L. (2012). Cell phone activities 2012. Washington, D.C.: Pew Internet \& American Life Project.

Fahlman, S. A., Mercer-Lynn, K. B., Flora, D. B., \& Eastwood, J. D. (2013). Development and validation of the multidimensional state boredom scale. Assessment, 20(1), 68-85.

Ginsburg, K. R., Winston, F. K., Senserrick, T. M., García-España, F., Kinsman, S., Quistberg, D. A., ... Elliott, M. R. (2008). National young-driver survey: Teen perspective and experience with factors that affect driving safety. Pediatrics, 121(5), e1391-1403.

Goodman, A. (1990). Addiction: Definition and implications. British Journal of Addiction, 85(11), 1403-1408.

Gostin, L. O., \& Jacobson, P. D. (2010). Reducing distracted driving: Regulation and education to avert traffic injuries and fatalities. The Journal of the American Medical Association, 303(14), 1419-1420.

Hair, J. F., Hult, G. T. M., Ringle, C. M., \& Sarstedt, M. (2014). A primer on partial least squares structural equation modeling (PLS-SEM). Thousand Oaks, CA: Sage.

Highway Loss Data Institute. (2010). Texting bans aren't reducing crashes in 4 states where they've been enacted, insurance data reveal. Status Report, 45(10), 1-3.

Hwang, H. S., \& Lombard, M. (2006). Understanding instant messaging: Gratifications and social presence. 9th Annual International Workshop on Presence (pp. 50-56).

Igarashi, T., Motoyoshi, T., Takai, J., \& Yoshida, T. (2008). No mobile, no life: Self-perception and text-message dependency among Japanese high school students. Computers in Human Behavior, 24(5), 2311-2324.

Kim, J., LaRose, R., \& Peng, W. (2009). Loneliness as the cause and the effect of problematic Internet use: The relationship between Internet use and psychological well-being. CyberPsychology \& Behavior, 12(4), 451-455.

Kircher, K., Patten, C., \& Ahlstrom, C. (2011). Mobile telephones and other communication devices and their impact on traffic safety. A review of the literature. Linkoping, Sweden: VTI.

Krishnatray, P., Singh, P. P., Raghavan, S., \& Varma, V. (2010). Gratifications from new media: Gender differences in Internet use in cybercafes. Journal of Creative Communications, 4(1), 19-31.

Krosnick, J. A., \& Presser, S. (2009). Question and questionnaire design. In P. V Marsden \& J. D. Wright (Eds.), Hanbook of Survey Research (pp. 263-314). Bingley, United Kingdom: Emerald Group.

Leary, M. R. (1983). A brief version of the fear of negative evaluation scale. Personality and Social Psychology Bulletin, 9(3), 371-375. 
Lenhart, A. (2012). Teens, smartphones \& texting. Washington, D.C.: Pew Internet \& American Life Project.

Leung, L. (2008). Leisure boredom, sensation seeking, self-esteems, addiction symptoms and patterns of mobile phone use. In Mediated Interpersonal Communication (pp. 359-382). New York, NY: Routledge.

Levy, Y. (2008). An empirical development of critical value factors (CVF) of online learning activities: An application of activity theory and cognitive value theory. Computers \& Education, 51(4), 1664-1675.

Liu, I. L. B., Cheung, C. M. K., \& Lee, M. K. O. (2010). Understanding Twitter usage: What drive people continue to tweet. Proceedings of the Pacific Asia Conference on Information Systems (pp. 927-939). Taipei, Taiwan.

Lu, X., Watanabe, J., Liu, Q., Uji, M., Shono, M., \& Kitamura, T. (2011). Internet and mobile phone text-messaging dependency: Factor structure and correlation with dysphoric mood among Japanese adults. Computers in Human Behavior, 27(5), 1702-1709.

Mansell, W., Clark, D. M., Ehlers, A., \& Chen, Y.-P. (1999). Social anxiety and attention away from emotional faces. Cognition \& Emotion, 13(6), 673-690.

McKenna, K. Y. A., Green, A. S., \& Gleason, M. E. J. (2002). Relationship formation on the Internet: What's the big attraction? Journal of Social Issues, 58(1), 9-31.

Meerkerk, G.-J., Van Den Eijnden, R. J. J. M., Vermulst, A. A., \& Garretsen, H. F. L. (2009). The compulsive Internet use scale (CIUS): Some psychometric properties. CyberPsychology \& Behavior, 12(1), 1-6.

Mikulas, W. L., \& Vodanovich, S. J. (1993). The essence of boredom. Psychological Record, 43(1), 3-10.

Nemme, H., \& White, K. M. (2010). Texting while driving: Psychosocial influences on young people's texting intentions and behaviour. Accident Analysis \& Prevention, 42(4), 12571265.

O'Brien, N. P., Goodwin, A. H., \& Foss, R. D. (2010). Talking and texting among teenage drivers: A glass half empty or half full? Traffic Injury Prevention, 11(6), 549-554.

Olson, R. L., Hanowski, R. J., Hickman, J. S., \& Bocanegra, J. (2009). Driver distraction in commercial vehicle operations. Blacksburg, VA: Virginia Tech Transporation Institute.

Reid, D. J., \& Reid, F. J. M. (2005). Textmates and text circles: Insights into the social ecology of SMS text messaging. In Mobile World (pp. 105-118). London, England: Springer.

Reid, F. J. M., \& Reid, D. J. (2010). The expressive and conversational affordances of mobile messaging. Behaviour \& Information Technology, 29(1), 3-22.

Rudin-Brown, C. M., Young, K. L., Patten, C., Lenné, M. G., \& Ceci, R. (2012). Driver distraction in an unusual environment: Effects of text-messaging in tunnels. Accident Analysis \& Prevention, 50, 122-129.

Rutland, J. B., Sheets, T., \& Young, T. (2007). Development of a scale to measure problem use of short message service: The SMS problem use diagnostic questionnaire. CyberPsychology 
\& Behavior, 10(6), 841-843.

Sekaran, U. (2003). Research methods for business: A skill building approach. New York, NY: John Wiley \& Sons Inc.

Shaw, M., \& Black, D. W. (2008). Internet addiction: Definition, assessment, epidemiology and clinical management. CNS Drugs, 22(5), 353-365.

Skierkowski, D., \& Wood, R. M. (2012). To text or not to text? The importance of text messaging among college-aged youth. Computers in Human Behavior, 28(2), 744-756.

Smith, M. L., Benden, M. E., \& Lee, C. (2012). Promoting active communities in a culture of distracted driving. Preventing Chronic Disease, 9, 10-12.

Snowden, C. (2006). Casting a powerful spell: The evolution of SMS. In A. Kavoori \& N. Arceneaux (Eds.), The Cell Phone Reader (pp. 107-124). New York, NY.

Stafford, T. F., Stafford, M. R., \& Schkade, L. L. (2004). Determining uses and gratifications for the Internet. Decision Sciences, 35(2), 259-288.

Strayer, D. L., Watson, J. M., \& Drews, F. A. (2011). Cognitive distraction while multitasking in the automobile. In The Psychology of Learning and Motivation (pp. 29-58). Burlington: Academic Press.

Tufte, E. R. (2001). The visual display of quantitative information. Cheshire, CT: Graphics Press LLC.

U.S. Department of Transportation. (2010). Distracted driving 2009 (DOT HS 811 379). Washington, D.C.: National Highway Traffic Safety Administration.

Walsh, S. P., White, K. M., Hyde, M. K., \& Watson, B. C. (2008). Dialing and driving: Factors influencing intentions to use a mobile phone while driving. Accident Analysis \& Prevention, 40(6), 1893-1900.

Wilson, F. A., \& Stimpson, J. P. (2010). Trends in fatalities from distracted driving in the United States, 1999 to 2008. American Journal of Public Health, 100(11), 2213-2219.

Young, K. S. (1998). Internet addiction: The emergence of a new clinical disorder. CyberPsychology \& Behavior, 1(3), 237-244.

\section{Authors' Biographies}

Dr. Nathan White is an Assistant Professor at Central Washington University in the Information Technology and Administrative Management Department where he teaches networking, cybersecurity, and database courses at the undergraduate and graduate levels. He obtained his Ph.D. in Information Systems from Nova Southeastern University. He has also earned an undergraduate degree in computer science from the University of Maryland, a Master of Business Administration degree from St. Mary's University, and a Master of Science in Computer Information Systems degree from Southern Illinois University-Edwardsville. Prior to joining the faculty at Central Washington University, he was a member of the faculty of the Computing Division at McKendree University. Dr. White is also a retired officer of the United 
States Air Force, where he served from 21 years. After retiring from the Air Force and prior to entering academia, he was an Associate Vice President in the IT department of a Fortune 500 financial services company.

Dr. Yair Levy is a Professor of Information Systems and Cybersecurity at the College of Engineering and Computing, at Nova Southeastern University, the Director of the Center for eLearning Security Research (CeLSR), and chair of the Information Security Faculty Group at the college along with serving as the director of the Ph.D. program in Information Assurance. He joined the university in 2003, was promoted to an Associate Professor in 2007, and to full Professor in 2012. During the mid to late 1990s, Dr. Levy assisted NASA to develop e-learning platforms as well as manage Internet and Web infrastructures. He earned his undergraduate degree in Aerospace Engineering from the Technion (Israel Institute of Technology). He received his Masters of Business Administration (MBA) with Management Information Systems (MIS) concentration and Ph.D. in MIS from Florida International University. He heads the Levy CyLab, which conducts innovative research from the human-centric lens of four key research areas Cybersecurity, User-authentication, Privacy, and Skills (CUPS), as well as their interconnections. He authored over 60 articles, three book chapters, one book, and his publications have been cited for over 1,400 times by other scholarly research. Dr. Levy has been an active member of the US Secret Service (USSS)'s - Miami Electronic Crimes Task Force (MECTF) and The South Florida Cybercrime Working Group (SFCWG). He was trained by the Federal Bureau of Investigation (FBI) on various topics, and actively serves as a member of the FBI/InfraGard, and consults the FBI/Cyber Task Force (CTF). Dr. Levy serves on the national Joint Task Force of Cybersecurity Education, as well as other national initiatives related to cybersecurity workforce, education, and research. He is also a frequent invited keynote speaker at national and international meetings, as well as regular media interviews as a Subject Matter Expert (SME) on cybersecurity topics. Find out more about Dr. Levy and his research lab via: http://cec.nova.edu/ levyy/

Dr. Steve Terrell is a Professor in the College of Engineering and Computing, and the Fischler College of Education, at Nova Southeastern University where he teaches quantitative and qualitative research methods. His Ph.D. is in Higher Education with Masters in Counseling and Business. He is the author of two textbooks focusing on developing dissertation proposals and inferential statistics. Steve has published over 100 journal articles and presentations focusing primarily on student motivation, achievement and attrition at all levels of education. Steve currently serves as chair of the American Educational Research Association's Online Teaching and Learning Special Interest Group and is active in EDUCAUSE, the International Society for Technology in Education and the American Counseling Association.

Dr. Steve E. Bronsburg received his Doctorate of Philosophy (Ph.D.) and Master of Science (M.S.) degrees in Information Systems from Nova Southeastern University's (NSU) Graduate School of Computer Information Systems (GSCIS) now renamed the College of Engineering and Computing. He also holds a Master of Health Services Administration (M.H.S.A.) degree from Florida International University (F.I.U.), and is a Certified Tobacco Treatment Specialist (C.T.T.S.) through the University of Medicine and Dentistry in New Jersey (UMDNJ). Dr. Bronsburg is an Assistant Professor at NSU in the College of Osteopathic Medicine's (COM's) Biomedical Informatics Program. Prior to his faculty appointment, Dr. Bronsburg served as the Assistant Director of the state funded Tobacco Training and Cessation Program at the NSU 
COM's Area Health Education Center (AHEC). Dr. Bronsburg authored and co-authored several presentations and articles on the AHEC Tobacco Program at the Annual Meetings of the American Public Health Association and for the National AHEC Organization. In addition, Dr. Bronsburg has work on several grant funded projects including avatar training modules for healthcare providers and developed a smartphone application to help address individuals working on reducing their alcohol use. He has just completed a research project focused on a text reminder and support system for tobacco cessation. He has written about the role of information technology project management in healthcare, he has co-authored articles on the NSU COM Biomedical Informatics Program, given presented on HIPAA and Meaningful Use, smart phone applications, and continues to be involved in healthcare technology related research. Dr. Bronsburg currently serves as a program committee member for the International Institute for Applied Knowledge Management Conference. 